\title{
Improved Procedure for Immunogold Electron Microscopy: Rapid-Freeze Substitution with Absolute Acetone
}

\author{
Hidenori Takahashi ${ }^{1, *}$, Haruko Kuroiwa ${ }^{2}$, Shin-ya Miyagishima $^{1}$, Kyoko Toda $^{1}$, \\ Ryuuichi Itoh $^{1}$, and Tsuneyoshi Kuroiwa ${ }^{1}$ \\ ${ }^{1}$ Department of Biological Sciences, Graduate School of Science, \\ University of Tokyo, Hongo, Tokyo 113, Japan \\ ${ }^{2}$ Kyoritsu Women's Junior College, Kanda, Tokyo 102, Japan
}

Accepted July 23, 1997

Improvements in fixative reagents have greatly facilitated the ultrastructural observation of the intracellular structure of various organisms by electron microscopy. Although fixatives are thought to be necessary to preserve the integrity of structures, they sometimes reduce the antibody reactivity in immunoelectron microscopy. Therefore, if samples are used as "raw" condition, epitopes for immuno-reactions are not blocked and high reactivities will be obtained. The appearance of cryomicrotomes was the response for such needs. But if the sensitivities in the immuno-reactions on the thin sections can be elevated by slightly modifying familiar equipment and methods for resin-embedding, such would be convenient. Moreover, resin-embedded specimens have an advantage of being stored for later investigations.

The effects of fixatives on antigenicity and the properties of the embedding resin have been well studied (for example, see Hayat 1989), but in this study, we re-examined these factors to find a more effective method for immunoelectron microscopy. For this purpose, we chose a red alga Cyanidium caldarium RK-1 as a material. C. caldarium RK-1 is a unicellular eukaryote that has only one cell nucleus, one mitochondrion and one plastid per cell (Nagashima and Fukuda 1981) and clear filamentous elements; a plastid-dividing ring and a contractile ring (Mita et al. 1986, Mita and Kuroiwa 1988, Suzuki et al. 1995). The advantage of this organism is that these cellular elements can all be observed at the same time within a single small section, because the diameter of the cell is only 1-3 $\mu \mathrm{m}$ (Nagashima and Fukuda 1981). The small size of the cell also facilitates the examination of the large number of the cells.

Using this alga, we compared the preservation of intracellular structures in the differently processed cells. Then, the reactivity of the samples to anti-DNA antibodies was also examined based on the density of the gold particles on the cell nucleus.

\section{Materials and methods}

C. caldarium RK-1 cells were cultured in Allen's medium (Allen 1959) with shaking flasks under continuous light $\left(40 \mu \mathrm{E} / \mathrm{m}^{2} / \mathrm{s}\right)$ at $42^{\circ} \mathrm{C}$. Cells were collected in sampling tubes by a centrifugation at 3,000 rpm for $5 \mathrm{~min}$.

For chemical fixation, cell pellets were suspended in $1 \%$ glutaraldehyde (GA) dissolved in the medium for $12 \mathrm{hr}$ and then collected by centrifugation. The cells were resuspended in $2 \%$ SeaPlaque agarose (FMC, Rockland, ME, USA), which was pre-cooled to $42^{\circ} \mathrm{C}$, and stored at $4{ }^{\circ} \mathrm{C}$ until the agarose coagulated. This sample was cut into pieces and subjected to an ethanol series of $30 \%, 50 \%, 70 \%, 80 \%, 90 \%, 99 \%$ and $100 \%$ to dehydrate samples. Then, samples were infiltrated by LR White resin (London Resin Company, Berkshire, England) by gradually increasing the concentration of the resin, and finally embedded in $100 \% \mathrm{LR}$ White resin at $50^{\circ} \mathrm{C}$ for 2 days.

\footnotetext{
* Corresponding author: Tel: +81-3-3812-2111 (ex. 4471); Fax: +81-3-3814-1408.
} 
For rapid-freeze substitution, medium was removed as much as possible from the cell pellets by repeated centrifugation to avoid the formation of ice crystals. Cell pellets were sandwiched between small copper plates with a thickness of $20 \mu \mathrm{m}$ and dropped into liquid propane at $-190^{\circ} \mathrm{C}$. The frozen cells were transferred to acetone with or without $1 \% \mathrm{GA}$, or with $1 \% \mathrm{OsO}_{4}$, all of which were pre-cooled by dry ice, and stored in the refrigerator at $-80^{\circ} \mathrm{C}$ for $48 \mathrm{hr}$. Samples were then gradually warmed to $20^{\circ} \mathrm{C}$ by stepwise incubation at $-20^{\circ} \mathrm{C}, 0^{\circ} \mathrm{C}, 4^{\circ} \mathrm{C}$ and $20^{\circ} \mathrm{C}$ each for $2 \mathrm{hr}$. After samples were washed twice with fresh absolute acetone, they were gradually infiltrated by LR White resin or Spurr's resin (Spurr 1969) with the combinations listed in Table 1 and were embedded at $50^{\circ} \mathrm{C}$ or $70^{\circ} \mathrm{C}$ for 2 days, respectively.

Thin sections of the samples of about $100 \mathrm{~nm}$ thick were cut with a glass knife using an MT-7 Ultramicrotome (RMC-Eiko, Kawasaki, Japan). Immunogold labelling of the sectioned cells were performed according to the methods of Nozaki et al. (1994). As first antibodies, monoclonal antibodies against human single- and double-stranded DNA (Boehringer Mannheim, Mannheim, Germany) were used at a dilution of $1: 10$. As a second antibody, goat anti-mouse IgM conjugated to gold particles of $15 \mathrm{~nm}$ (EY Laboratories, San Mateo, CA, USA) was used at a dilution of 1:80. After double staining with uranyl acetate and lead citrate, samples were examined by electron microscopy (JEM-1200 EXII; JEOL, Tokyo, Japan).

\section{Results and discussion}

To determine an optimal fixation method for immunogold labelling, we compared four different methods as listed in Table 1. We examined samples to determine the extent to which the integrity of the intracellular structures was preserved and the level of reactivity to immunogold labelling. Chemical fixation with GA or rapid-freeze substitution with GA in acetone, and subsequent embedding in LR White resin are standard methods for immunoelectron microscopy. Fixation in $\mathrm{OsO}_{4}$ in acetone and embedding in Spurr's resin is usually applied for the structural observation of the cell. We also tested a method in which fixatives are not used to examine the effects of fixatives on intracellular substructure and antigenic sites.

Examination of intracellular morphology indicated that with all four methods, one cell nucleus, one mitochondrion and one plastid could be observed in interphase cells (Fig. 1). But in contrast to the rapid-freeze substituted cells (Figs. 1B-D), chemically fixed cells (Fig. 1A) showed: (1) The cell nucleus, mitochondrion and plastid as well as the whole cell were shrunk and their outlines waved; (2) phycobilisomes were not apparent in the plastid; (3) neither the plastid-dividing ring nor the contractile ring were observed in dividing cells (data not shown). Concerning to (1), we measured and compared the diameter of the sectioned cell which were cut at the center of the cell. The obtained "apparent" diameters of cells were shown in Table 1. When the living C. caldarium RK-1 cells before processing were observed under light microscope, the diameter of the cells was about $2.0-2.5 \mu \mathrm{m}$. Cells processed by rapid-freeze substitution had an equivalent diameter $(2.1-2.3 \pm$ $0.2 \mu \mathrm{m}$; Table 1) whereas the diameter of chemically fixed cells was reduced (1.5 $\pm 0.1 \mu \mathrm{m}$; Table 1$)$. There were no outstanding differences between the ultrastructural images of the three kind of rapidfreeze substituted cells except that membranes were a little bit better defined in cells fixed by $\mathrm{OsO}_{4}$ and embedded in Spurr's resin (Fig. 1D). These observations indicate that rapid-freeze substitution is superior to chemical fixation for the preservation of the integrity of structures.

Concerning to the reactivities in the immunogold labelling, Morita et al. (1997) observed more than twice density of gold particles in cells rapid-freeze substituted with GA than in chemicallyfixed cells. The rapid-freeze substitution technique therefore surpasses the chemical fixation not only in its conservation of the intracellular structures but also in sensitivity in immunogold labelling.

To clarify the best method for immunogold labelling, we then compared the immuno-reactivity 
Table 1. Comparison of four different processing methods for electron microscopy and apparent diameter $(\mu \mathrm{m} \pm \mathrm{SD})$ of the C. caldarium RK-1 cells observed after each processing

\begin{tabular}{lllll}
\hline \hline \multicolumn{1}{c}{ Fixation } & \multicolumn{1}{c}{ Fixative } & Resin & Diameter $(\mu \mathrm{m})$ & $\mathrm{n}^{*}$ \\
\hline Chemical fixation & Acetone+1\% GA & LR White & $1.5 \pm 0.1$ & 25 \\
Rapid-freeze substitution & Acetone only & LR White & $2.1 \pm 0.2$ & 25 \\
& Acetone+1\% GA & LR White & $2.2 \pm 0.2$ & 25 \\
& Acetone $+1 \% \mathrm{OsO}_{4}$ & Spurr's & $2.3 \pm 0.2$ & 25 \\
\hline
\end{tabular}

* Number of cell sections examined.

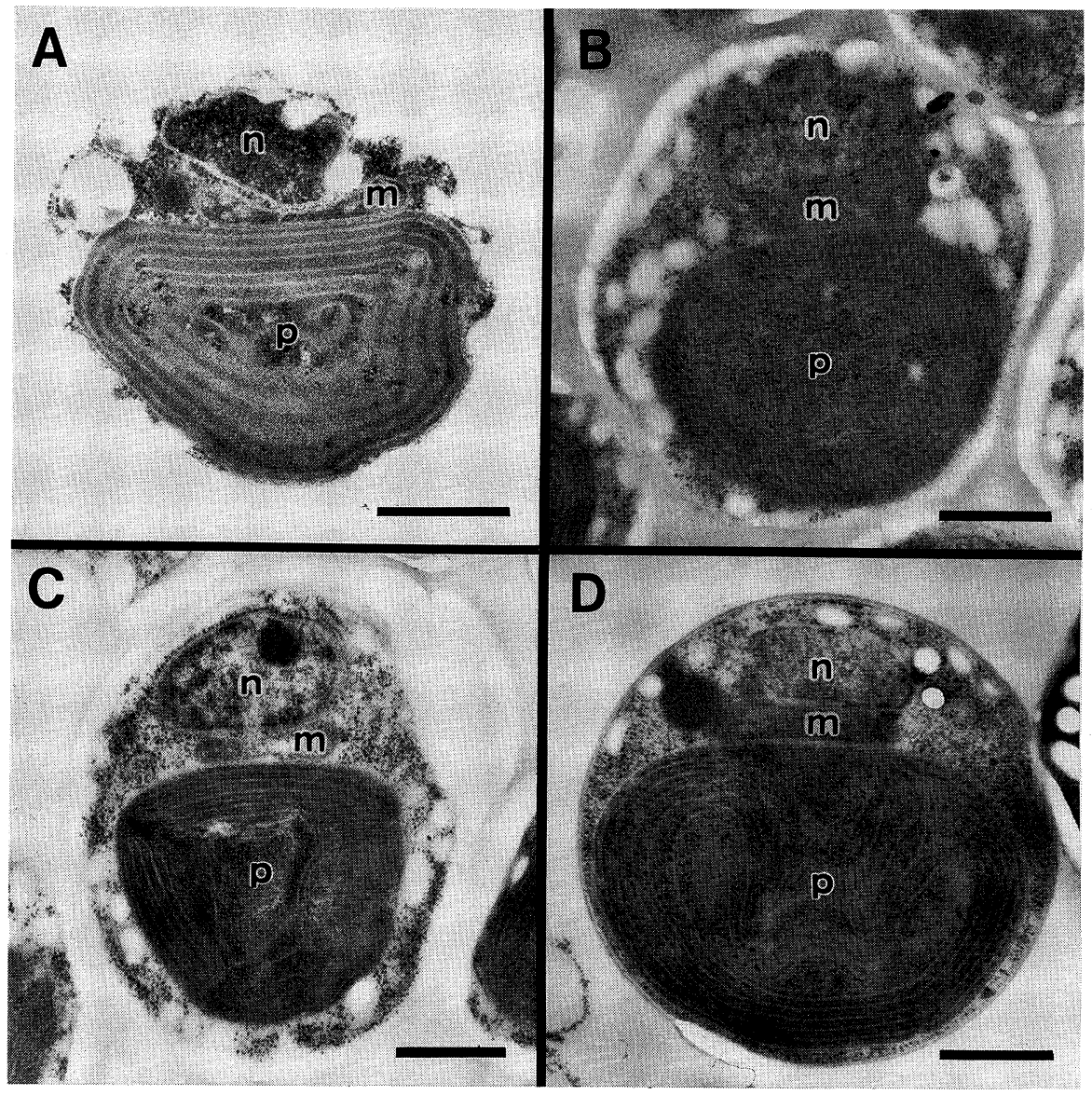

Fig. 1. Electron micrographs of interphase cells of $C$. caldarium RK-1 processed by four different methods. (A) Cells fixed by conventional chemical fixation and embedded in LR White resin. (B, C) Cells rapid-freeze substituted in acetone without (B) or with (C) $1 \%$ GA and embedded in LR White resin. (D) Cells rapid-freeze substituted with $1 \% \mathrm{OsO}_{4}$ in acetone and embedded in Spurr's resin. Alphabetic symbols represent cell nucleus (n), mitochondrion (m) and plastid (p). Scale bars represent $0.5 \mu \mathrm{m}$.

in the three differently rapid-freeze substituted samples by using monoclonal antibody against DNA. In cells fixed with acetone with or without $1 \%$ GA and embedded in LR White resin, many gold particles were specifically observed on the cell nuclei, and some were seen on the plastids (Figs. 2A-C). Very few gold particles were seen on the mitochondria. The numbers of gold parti- 


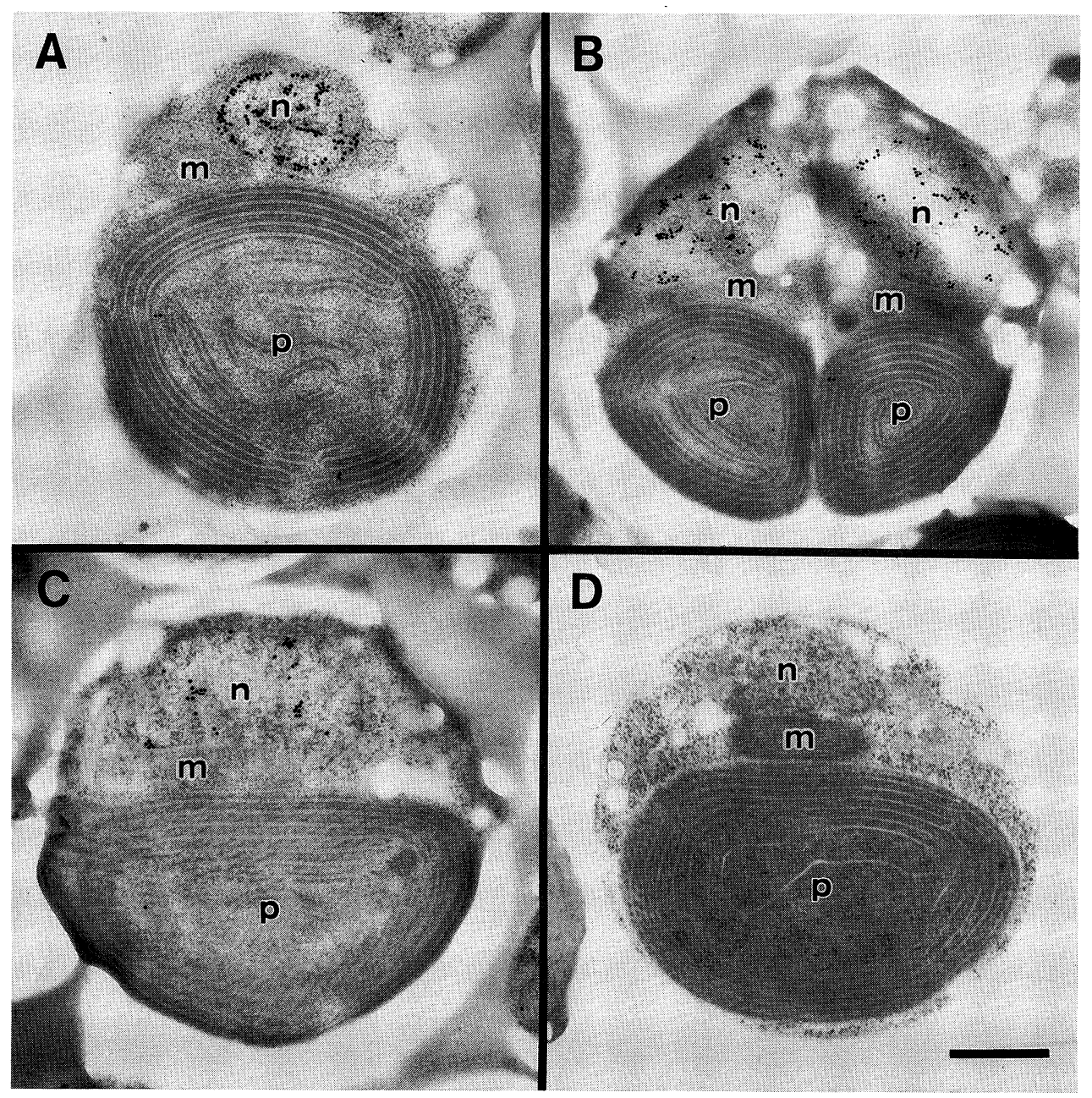

Fig. 2. Electron micrographs illustrating immuno-labelling for DNA of the rapid-freeze substituted $C$. caldarium RK-1 cells. (A, C, D) Interphase cells. (B) Cells after the first cell division. (A-C) Cells rapid-freeze substituted in acetone without $(\mathrm{A}, \mathrm{B})$ or with $(\mathrm{C}) 1 \% \mathrm{GA}$ and embedded in LR White resin. (D) Cells rapid-freeze substituted with $1 \% \mathrm{OsO}_{4}$ in acetone and embedded in Spurr's resin. Alphabetic symbols represent cell nucleus (n), mitochondrion (m) and plastid (p). Scale bar represents $0.5 \mu \mathrm{m}$.

Table 2. Densities of immunogold particles $\left(\mu \mathrm{m}^{-2} \pm \mathrm{SD}\right)$ on the cell nucleus of the interphase $C$. caldarium $\mathrm{RK}-1$ cells when antibodies against DNA were used

\begin{tabular}{llcc}
\hline \hline \multicolumn{1}{c}{ Fixative } & Resin & Density & $\mathrm{n}^{*}$ \\
\hline Acetone only & LR White & $309.5 \pm 79.6$ & 25 \\
Acetone $+1 \% \mathrm{GA}^{\prime}$ & LR White & $119.8 \pm 64.0$ & 25 \\
Acetone $+1 \% \mathrm{OsO}_{4}$ & Spurr's & 0 & 25 \\
\hline
\end{tabular}

* Number of cell sections examined.

cles observed on these organelles clearly reflected their DNA content (Suzuki et al. 1992, N. Ohta, personal communication). Furthermore, when cells were examined after the first cell division, equivalent numbers of the gold particles were observed on the two daughter cell nuclei (Fig. 2B). Methods and results in this study were therefore reliable. When cells were rapid-freeze substituted 
in acetone with $1 \% \mathrm{OsO}_{4}$ and embedded in Spurr's resin, no gold particles could be observed on the cell nucleus, mitochondrion or plastid (Fig. 2D). This lack of reactivity may reflect the hydrophobicity of the Spurr's resin, in contrast to the hydrophilic nature of the LR White resin (Carlemalm et al. 1982, Newman et al. 1983). Another possibility is that, as described by Roth et al. (1981) and Bendayan (1984), the epitopes on DNA molecules identified by the antibodies against DNA may be blocked when fixed by $\mathrm{OsO}_{4}$ since this fixative is stronger than GA.

To quantify the obtained reactivities, we calculated the densities of gold particles on the cell nucleus of interphase cells (Table 2). Cells fixed by absolute acetone had a 2.6-fold greater density of gold particles compared to the GA-fixed cells. Although GA is a weaker fixative than $\mathrm{OsO}_{4}$, crosslinks in the DNA may prevent antibodies from reacting with some parts of their epitopes as discussed by Bullock (1984).

In conclusion, rapid-freeze substitution in absolute acetone and embedding in LR White resin is the best method for immunogold labelling based on both the conservation of intracellular structures and immuno-reactivity. Thin sections of the samples embedded in the LR White resin can be also used for other purposes such as staining with 4',6-diamidino-2-phenylindole (DAPI), indirect immunofluorescence staining and enzymatic reactions (data not shown). Since rapid-freeze substitution with absolute acetone maintains the highest structural integrity in samples and keeps high antigenicity, application of this useful fixation method for various purposes will progress the utilities of LR White resin, and will bring us much more information about biological phenomena such as the localization of the biological molecules, ultrastructures of organelles, and so on.

\section{Summary}

We investigated the best fixation methods for the immunogold electron microscopy. Rapidfreeze substitution is better than conventional chemical fixation for preservation of structural integrity of cell nucleus, mitochondrion and plastid. When samples were embedded in LR White resin, fixation in absolute acetone gave a 2.6-fold increase in immuno-labelling of DNA compared to fixation with $1 \%$ glutaraldehyde in acetone. In contrast, no gold particles were identified when cells were fixed by $1 \% \mathrm{OsO}_{4}$ and embedded in Spurr's resin. These results indicate that the rapidfreeze substitution in absolute acetone and embedding in LR White resin is the optimal approach for immunogold labelling.

Abbreviations: GA, glutaraldehyde; DAPI, 4',6-diamidino-2-phenylindole.

\section{Acknowledgements}

The authors thank Dr. S. Kawano and Dr. H. Takano of the University of Tokyo for their kindness of the critical reading of the manuscript and useful comments whilst carrying out this study. This research was supported by grants (to T. K.) for Special Research on Priority Areas (project no. 06101002) from the Ministry of Education, Science, and Culture of Japan.

\section{References}

Allen, M. B. 1959. Studies with Cyanidium caldarium, an anomalously pigmented chlorophyte. Arch. Microbiol. 32: 270277.

Bendayan, M. 1984. Protein-A gold electron microscopic immunocytochemistry: Methods, applications and limitations. J. Electron Microsc. Tech. 1: 243-270.

Bullock, G. R. 1984. The current status of fixation for electron microscopy: A review. J. Microsc. 133: 1-15.

Carlemalm, E., Garavito, R. M. and Villiger, W. 1982. Resin development for electron microscopy and an analysis of embedding at low temperature. J. Microsc. 126: 123-143. 
Hayat, M. A. 1989. Colloidal gold: Principles, methods, and applications. Vol. 2. Academic Press, San Diego, California.

Mita, T., Kanbe, T., Tanaka, T. and Kuroiwa, T. 1986. A ring structure around the dividing plane of the Cyanidium caldarium chloroplast. Protoplasma 130: 211-213.

- and Kuroiwa, T. 1988. Division of plastids by a plastid-dividing ring in Cyanidium caldarium. Protoplasma Suppl. 1: 133-152.

Morita, E., Kuroiwa, H., Kuroiwa, T. and Nozaki, H. 1997. High localization of ribulose-1,5-bisphosphate carboxylase/oxygenase in the pyrenoids of Chlamydomonas reinhardtii (Chlorophyta), as revealed by cryofixation and immunogold electron microscopy. J. Phycol. 33: 68-72.

Nagashima, H. and Fukuda, I. 1981. Morphological properties of Cyanidium caldarium and related algae in Japan. Jpn. J. Phycol. 29: 237-242.

Newman, G. R., Jasani, B. and Williams, E. D. 1983. A simple postembedding system for the rapid detection of tissue antigens under the electron microscope. Histochem. J. 15: 543-555.

Nozaki, H., Kuroiwa, H. and Kuroiwa, T. 1994. Light and electron microscopic characterization of two types of pyrenoids in Gonium (Goniaceae, Chlorophyta). J. Phycol. 30: 279-290.

Roth, J., Bendayan, M., Carlemalm, E., Villiger, W. and Garavito, M. 1981. Enhancement of structural preservation and immunocytochemical staining in low temperature embedded pancreatic tissue. J. Histochem. Cytochem. 29: 663671.

Spurr, A. R. 1969. A low-viscosity epoxy resin embedding medium for electron microscopy. J. Ultrastruct. Res. 26 : 31-43.

Suzuki, K., Ohta, N. and Kuroiwa, T. 1992. Isolation of the cell-nuclear, mitochondrial, and chloroplast DNA from the ultrasmall eukaryote Cyanidioschyzon merolae. Protoplasma 171: 80-84.

-, Kawazu, T., Mita, T., Takahashi, H. and Kuroiwa, T. 1995. Cytokinesis by a contractile ring in the primitive red alga Cyanidium caldarium RK-1. Eur. J. Cell Biol. 67: 170-178. 